\title{
Drug Susceptibility Pattern and Associated Factors of Bacteria Isolated from Urinary Tract Infection among Pregnant Women Attending Antenatal Care in Teaching Hospital, Southeast Ethiopia
}

\section{Eshetu Nigussie ( $\nabla$ eshetunba@gmail.com )}

Department of Medical Laboratory Science, School of Medicine, Madda Walabu University Goba Referral hospital, Bale-Goba, Ethiopia

Meseret Mitiku

Department of Medical Laboratory Science, School of Medicine, Madda Walabu University Goba Referral hospital, Bale-Goba, Ethiopia

\section{Alelign Tasew}

2Department of Public Health, School of Health Science, Madda Walabu University Goba Referral hospital, Bale-Goba, Ethiopia

\section{Biniyam sahiledengel}

2Department of Public Health, School of Health Science, Madda Walabu University Goba Referral hospital, Bale-Goba, Ethiopia

\section{Damtew Solomon}

Department of Biomedical Sciences, School of Medicine, Madda Walabu University Goba Referral hospital, Bale-Goba, Ethiopia

\section{Habtamu Gezahegn}

Department of Biomedical Sciences, School of Medicine, Madda Walabu University Goba Referral hospital, Bale-Goba, Ethiopia

\section{Aklil Astatike}

Madda Walabu University Goba Referral hospital Laboratory, Bale-Goba, Ethiopia

\section{Getahun Negash}

Department of Medical Laboratory Science, School of Medicine, Madda Walabu University Goba Referral hospital, Bale-Goba, Ethiopia

\section{Research Article}

Keywords: UTI, Bacterial profile, Drug susceptibility testing, Ethiopia

Posted Date: January 8th, 2021 
DOl: https://doi.org/10.21203/rs.3.rs-118159/v1

License: (c) (1) This work is licensed under a Creative Commons Attribution 4.0 International License. Read Full License 
1 Drug Susceptibility Pattern and Associated Factors of Bacteria Isolated from Urinary Tract

2 Infection among Pregnant Women Attending Antenatal Care in Teaching Hospital,

3 Southeast Ethiopia

4 Eshetu Nigussie $^{1 *}$, Meseret Mitiku ${ }^{1}$, Alelign Tasew ${ }^{2}$, Biniyam Sahiledengel $^{2}$, Damtew Solomon $^{3}$, 5 Habtamu Gezahegn ${ }^{3}$, Aklil Astatike ${ }^{4}$, Getahun Negash ${ }^{1}$

6

$7 \quad{ }^{1}$ Department of Medical Laboratory Science, School of Medicine, Madda Walabu University Goba

8 Referral hospital, Bale-Goba, Ethiopia

$9 \quad{ }^{2}$ Department of Public Health, School of Health Science, Madda Walabu University Goba Referral 10 hospital, Bale-Goba, Ethiopia

$11{ }^{3}$ Department of Biomedical Sciences, School of Medicine, Madda Walabu University Goba

12 Referral hospital, Bale-Goba, Ethiopia

$13 \quad{ }^{4}$ Madda Walabu University Goba Referral hospital Laboratory, Bale-Goba, Ethiopia

$14 *$ Corresponding author, email: eshetunba@gmail.com

15

16

17

18

19

20

21

22

23

24

25

26

27

28

29 


\section{ABSTRACT}

Background: Urinary tract infections are caused by bacteria from the digestive tract which climbs the opening of the urethra and begins to multiply to cause infection. This study aimed to assess the bacterial profile and antibiotic susceptibility pattern and associated risk factors among pregnant women in Madda Walabu University Goba Referral Hospital, Southeast Ethiopia.

Methods: An institution-based cross-sectional study was conducted from June-August, 2019. A total of 234 pregnant women were enrolled; data were collected using a structured questionnaire by a trained interviewer. Urine samples were collected from all pregnant women and culture on cysteine lysine electrolytes deficiency medium. Data were analyzed using SPSS 20.0. Descriptive statistics were used to explain the study participants with relevant variables. Logistic regression was used for data comparison. P-value $<0.05$ was accepted as statistically significant.

Results: The overall prevalence of UTIs was $23.9 \%$ among both asymptomatic and symptomatic groups. Of this screened midstream urine samples showed that $16 \%$ and $32.2 \%$, had significant bacteriuria in the asymptomatic and symptomatic groups respectively. The prevalence of UTIs was significantly associated with previous history of catheterization and urinary tract infection. E. coli was the most frequently isolated organism (42.9\%) followed by coagulase-negative Staphylococcus (26.8\%), and S. aureus (12.5\%). Gram-negative and Gram-positive bacteria 47 accounted for (59\%) and (41\%) respectively.

Conclusion: Significant bacteriuria has been observed from both symptomatic and asymptomatic pregnant women. The majority of the isolates were resistant to commonly prescribed antibiotics. This calls for an early screening of all pregnant women for UTI and those found to be infected need treatment.

52 Keywords: UTI, Bacterial profile, Drug susceptibility testing, Ethiopia 
59 Urinary tract infections (UTIs) are an infection caused by the presence and growth of microorganisms anywhere in the urinary system. The source of these microorganisms is usually

61 from the digestive system which climbs the urinary tract and starts to multiply to cause infection

$62[1-3]$. The range of infection varies, from asymptomatic (the bacteria present in urine but not show 63 symptoms) to symptomatic (the bacterial infection shows symptoms). Due to short urethra, 64 absence of prostatic secretion, pregnancy and easy contamination of the urinary tract with fecal 65 flora women are more susceptible to UTIs than men [4,5]. In most developing countries including 66 Ethiopia, screening for UTIs in pregnancy is not considered an essential part of antenatal care. It 67 has been estimated that globally symptomatic UTIs result in as many as seven million visits to 68 outpatient clinics, one million visits to emergency departments, and 100,000 hospitalizations 69 annually $[6,7]$.

Due to several anatomical and hormonal changes, pregnant women are more susceptible to develop

72 UTIs. Perhaps if untreated, it can lead to serious obstetric complications, poor maternal and 73 prenatal outcomes. Furthermore, it has been observed that asymptomatic bacteriuria can lead to 74 cystitis and pyelonephritis which can lead to acute respiratory distress, transient renal failure, 75 sepsis and shock during pregnancy [5,8]. In pregnancy, pyelonephritis increases the risk of preterm labor and delivery which results in prematurity and low birth weight with high perinatal morbidity 77 and mortality [9].

79 The causative agents of UTIs most of the time are Gram-negative aerobic rods found in the digestive system. The most common are: E. coli, K. pneumoniae, Enterobacter, Citrobacter, P.

81 mirabilis, and P. aeruginosa. Other common pathogens include S. epidermidis, S. saprophyticus,

82 Enterococcus species and Serratia species which presumably result in UTIs following colonization

83 of the genito-urinary tract [10]. E.coli (60-70\%), Klebsiella species (10\%), Proteus species (584 10\%) and Pseudomonas species (2-5\%) are the dominant Gram-negative bacteria causing UTIs. 85 Among Gram-positive bacteria pathogens, Streptococcus species and Staphylococcus species are 86 frequently isolated from cases of UTIs [11,12]. 
Many factors were identified which aggravate the probability of acquiring UTIs causing pathogens during pregnancy, including the history of UTIs, sexual activity, history of catheterization, lower socioeconomic status, and multiparity $[4,13]$.

Antimicrobial resistance among bacteria is a worldwide problem. The situation in developing countries like Ethiopia is a particularly serious issue [7]. Resistance in antimicrobial drugs in bacteria can result from two mutually nonexclusive phenomenons: mutations in housekeeping structural or regulatory genes and the horizontal acquisition of foreign genetic information [1416]. Treatment of UTIs cases is often started empirically and therapy should be based on information determined from the antibiotic resistance pattern of the identified isolates. However, a large proportion of uncontrolled antibiotic usage has contributed to the emerging of resistant bacterial infections. As a result, the prevalence of antibiotic resistance among uro-pathogens has been rising worldwide [7].

There are no similar previous studies conducted in Madda Walabu University Goba Referral Hospital (MWU GRH), where the antenatal care is provided for pregnant women. Therefore, this study was done to assess predominant isolates of uro-pathogens and their antibiotic susceptibility pattern and associated risk factors in pregnant women attending antenatal care in MWU GRH, Ethiopia. Also, this study was providing baseline information for further studies which will be conducted in the study area. The findings of the study were contributed to filling the gaps.

\section{METHODS}

\section{Study Design, Area and participants}

A hospital-based cross-sectional study was conducted at MWU GRH, which is located in Goba town, Oromia region, Southeast part of Ethiopia; $445 \mathrm{Km}$ from Addis Ababa. This town has a latitude and longitude of $7^{\circ} 0^{\prime} \mathrm{Nt} 39^{\circ} 59^{\prime} \mathrm{E}$ and an elevation of 2,743 meters above sea level. Goba referral hospital is the only referral and teaching hospital in Bale zone serving over 1,787,575 million people.This study was conducted from June to August, 2019. The study participants were all pregnant women who visited the MWU GRH during the study period and fulfilled inclusion criteria. 


\section{Sample size and sampling technique}

118 To determine the sample size single population proportion formula was used with the following assumptions: Based on the study conducted in Ambo, 18.7\% prevalence of UTI was observed [3]. Accordingly, the required sample size (n) was estimated with a confidence level of $95 \%$ and a $5 \%$ degree of precision. Thus the sample size was: 234

\section{Sampling technique}

123

A systematic random sampling technique was used in pregnant women who visited the Goba referral hospital during the data collection period were included in the study.

\section{Recruitment procedure}

Trained data collectors have approached all the pregnant women at the outpatient department of study sites, explain the purpose of the study and give out the study information sheet. For illiterate participants, the data collectors were read/other trusted individuals by the patient was read the information sheet. Literate participants were read information sheet by themselves. After allowing them to think and discuss attending all questions, the participants were asked to sign an informed consent in the presence of a literature witness.

\section{Sample and Data collection and processing}

Socio-demographic and clinical data related to UTIs collected using structured questionnaires. Ten $\mathrm{ml}$ freshly voided midstream urine specimens were collected and inoculated into CLED medium (Oxoid Ltd, Basingstoke, UK) using a calibrated wire inoculating loop $(0.001 \mathrm{ml})$. Cultures were incubated in an aerobic atmosphere at $37^{\circ} \mathrm{C}$ for $24 \mathrm{hrs}$. Colonies were counted to check the presence of significant bacteriuria. Colony count yielding bacterial growth of $10^{5} \mathrm{CFU} / \mathrm{ml}$ of urine was regarded as significant bacteriuria [17]. All positive cultures have had identified at the species level by their colony characteristics, gram-staining reaction and by the pattern of biochemical tests using standard protocols. The Gram-negative rods were identified by indole production, $\mathrm{H}_{2} \mathrm{~S}$ production, citrate utilization, motility test, urease utilization, and oxidase test. The Gram-positive bacteria were differentiated using catalase and coagulase tests [14].

The drug susceptibility pattern of all identified pathogens of urine samples was done using the Kirby-Bauer disk diffusion technique [18] according to the criteria of the Clinical and Laboratory 
Standards Institute method (CLSI 2018). Loopful bacterial colonies were taken from pure culture and transferred to a tube containing $5 \mathrm{ml}$ of normal saline to adjust the density of a McFarland 0.5. The cotton swab was used to distribute the bacteria evenly over the entire surface of MuellerHinton agar (Oxoid Ltd). By using sterile forceps, the following concentration of antibiotic discs

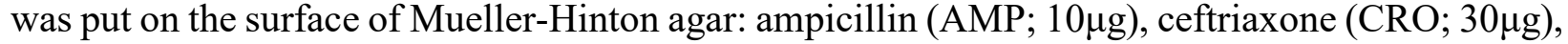

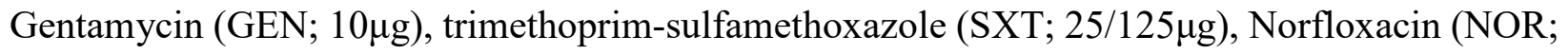

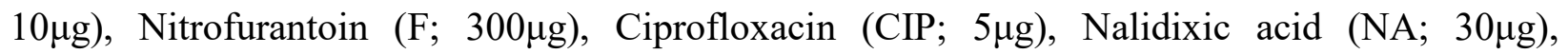

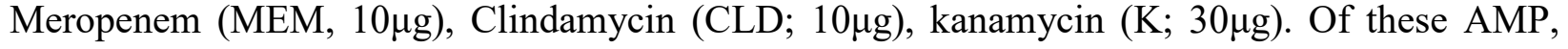
CRO, NA and MEM used only for Gram-negative bacteria, whereas CLD was used only for Grampositive bacteria and the rest antibiotics were used for both isolates.

\section{Data quality control issue}

The quality of data was assured by pre-testing of questionnaires on 20 participants in Robe hospital for assessing its clarity and to make amendments. The proper functioning of laboratory reagents and technical performance was checked daily by using reference strains (E. coli ATTC-25922, $S$. aureus ATCC-25923 and P. aerugenosa ATCC- 27853) before running patient samples and susceptibility testing and along with patient samples according to manufacturer guidlines.

\section{Data processing and analysis}

All questionnaires were checked visually, entered and cleaned using Epi-Data Version-3.2 and exported to Statistical Package for Social Science (SPSS) version 20.0 windows for analysis. For controlling errors, the questionnaire was double entered; and also frequency checks were done. To explain the study population with relevant variables descriptive statistics (frequencies, mean, standard deviation, and percentage) were used. Logistic regression was used to assess the association between outcome and explanatory variables. Associations between dependent and independent variables were assessed and its strength was described using odds ratios and $95 \%$ confidence intervals. P-value $<0.05$ was accepted as statistically significant.

\section{Ethical consideration}

Ethical clearance was obtained from the Madda Walabu University Institutional review board. Before any data collection, participants were informed about the aim of the study, about their right not to participate in the study or withdraw at any point in time and written consent was obtained. 
175 For illiterate participant the data collectors or other trusted individual by the patients were read the 176 information sheet. Literate participants were read information sheet by themselves. Personal 177 privacy and dignity were respected. All methods were carried out in accordance with relevant 178 guidelines and regulations. All samples and forms containing patient information were not having 179 a name or information that can identify a particular participant.

180

\section{RESULTS}

182 A total of 234 pregnant women with and without symptoms of UTIs were investigated from July183 August, 2019. The age of the study subjects ranged from 17 to 40 years with the majority (50\%) 184 in the age group of 15 to 24 years. The mean and median age was 24.94 and 24.5 years respectively. 185 The majority of study participants were housewives (71.8\%), followed by government employees 186 (13.7\%), urban dwellers (58.5\%) and have 1501-2000 Ethiopian birr (\$66.67) monthly income 187 (31.2\%). The educational status of participants varied from illiterate (26.1\%) to college and above 188 (12.4\%). Among the study participants, (91.5\%) were married and (68.4\%) multigravida. Above $18944 \%$ of the study subjects were in the second trimester (Table 1).

Table 1. Socio-demographic characteristics of study participants

\begin{tabular}{lcc}
\hline Characteristic & Number & Percentage \\
\hline Age & 117 & 50 \\
$15-24$ & 105 & 44.9 \\
$25-34$ & 12 & 5.1 \\
$35-44$ & & \\
Residence & 137 & 58.5 \\
Urban & 97 & 41.5 \\
Rural & & \\
Education level & 61 & 26.1 \\
Illiterate & 24 & 10.3 \\
Read and write & 59 & 25.2 \\
Primary & 61 & 26.1 \\
Secondary & 29 & 12.4 \\
College \& above & & \\
Monthly income (ETB) & &
\end{tabular}




$\begin{array}{lcc}<500(\$ 16.67) & 7 & 3 \\ 501-1000(\$ 16.7-33.33) & 46 & 19.7 \\ 1001-1500(\$ 33.4-50) & 60 & 25.6 \\ 1501-2000(\$ 50.03-66.67) & 73 & 31.2 \\ >2000(\$ 66.67) & 48 & 20.5\end{array}$

\section{Occupation}

Housewife

Employee

32

13.7

Merchant

23

9.8

Other

11

4.7

\section{Marital status}

Married

214

91.5

Divorced

16

6.8

Widowed

4

1.7

\section{Gestational stage}

First trimester

31

13.2

Second trimester

109

46.6

Third trimester

94

40.2

\section{Gestational category}

Primigravida

74

31.6

Multigravida

160

68.4

192 Others: students, day laborer

\section{Prevalence of UTI and Types of bacterial isolates}

194 From cultured urine specimens, significant bacteriuria was isolated in 56 (19 from asymptomatic 195 and 37 from symptomatic) pregnant women investigated for UTIs. The prevalence of bacteriuria 196 among symptomatic and asymptomatic pregnant women was $32.2 \%$ and $16 \%$ respectively, and 197 the overall prevalence was $23.9 \%$.

198 The percentage of each bacterium isolated from mid-stream urine samples is presented as shown 199 in the figure below. Of the total 56 isolates, Gram-negative bacteria were prevalent (59\%) than 
Gram-positive bacteria (41\%). The major isolated pathogens were E. coli (42.9\%), followed by coagulase-negative Staphylococci (CoNS) (26.8\%) (Figure 1.).

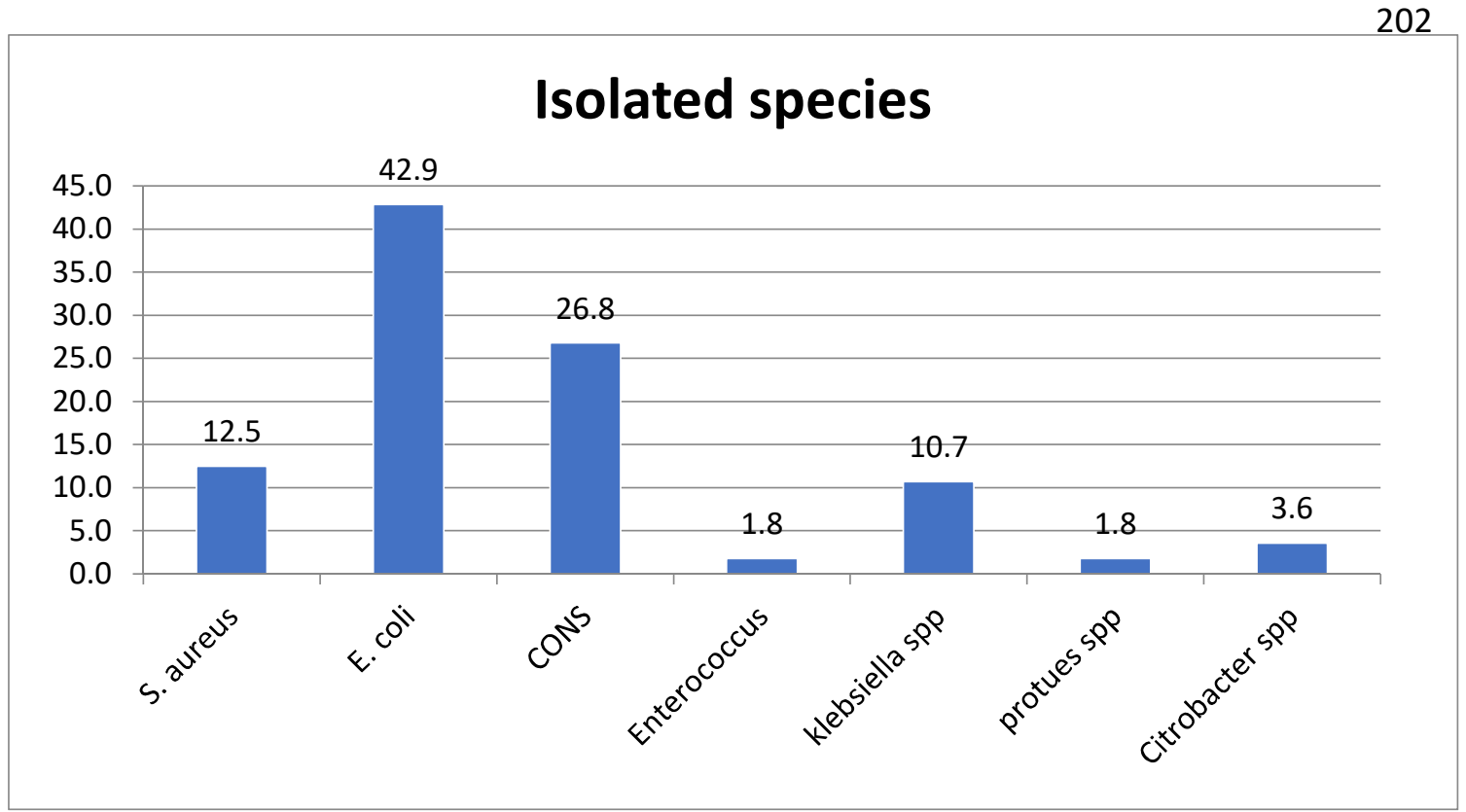

214 CONS - Coagulase-negative Staphylococcus

215 Figure 1. Bacterial isolates among pregnant women in MWU GRH, Southeast Ethiopia.

\section{Antimicrobial susceptibility testing of the isolates}

217 Gram-Negative Bacteria

218 Gram-negative pathogens showed a high level of sensitivity to GEN (90.9\%), and F (87.8\%). Of

219 these, E. coli in most clinical samples were highly sensitive to GEN (95.8\%), and F (86.7\%), but 220 resistant to AMP (58.3\%) and SXT (79.2\%). Klebsiella species were highly sensitive to GEN 221 (100\%). However, it was resistant to SXT (83.3\%) and NA (100). Citrobacter species and Proteus 222 species were also the most sensitive to GEN (100\%) and F (100\%), but 100\% resistant to AMP, 223 NA and SXT. In general Gram-negative isolates $(n=33)$ showed resistance rate of $60 \%$ to AMP, $22466.7 \%$ NA and $81.8 \%$ to SXT. Resistance against CRO, CIP, and NOR, was observed in the range 225 of 15-40\%. However, all Gram-negative bacterial isolates showed a low-level of resistance against 226 F and MEM (6.1\% and 9.1\%) respectively while no resistance against GEN (Table 2).

227 Table 2. Antimicrobial susceptibility testing of Gram-negative pathogens from urine culture in 228 pregnant women at Goba referral hospital, 2019 


\begin{tabular}{|c|c|c|c|c|c|c|c|c|c|c|c|}
\hline $\begin{array}{l}\text { Bacterial } \\
\text { isolate }\end{array}$ & $\begin{array}{r}\text { Total } \\
\text { no(\%) }\end{array}$ & & AMP & CRO & GEN & SXT & NOR & CIP & NA & MEM & $\mathbf{F}$ \\
\hline \multirow{3}{*}{ E.coli } & $24(42.9)$ & $\mathrm{S}$ & $5(20.8)$ & $10(41.7)$ & $23(95.8)$ & $3(12.5)$ & $17(70.8)$ & $13(54.2)$ & $3(12.5)$ & $17(70.8)$ & $22(86.7)$ \\
\hline & & I & $5(20.8)$ & $7(29.2)$ & $1(4.2)$ & $2(8.3)$ & $3(12.5)$ & $4(16.7)$ & $8(33.3)$ & $6(25)$ & $1(4.2)$ \\
\hline & & $\mathrm{R}$ & $14(58.3)$ & $7(29.2)$ & $0(0)$ & $19(79.2)$ & $4(16.7)$ & $7(29.2)$ & $13(54.2)$ & $1(4.1)$ & $1(4.2)$ \\
\hline Klebsiella & $6(10.7)$ & $\mathrm{S}$ & $3(50)$ & $1(16.7)$ & $6(100)$ & $1(16.7)$ & $5(83.3)$ & $5(83.3)$ & $0(0)$ & $4(66.7)$ & $4(66.7)$ \\
\hline \multirow[t]{2}{*}{ spp. } & & I & $0(0)$ & $2(33.3)$ & $0(0)$ & $0(0)$ & $0(0)$ & $0(0)$ & $0(0)$ & $1(16.7)$ & $1(16.7)$ \\
\hline & & $\mathrm{R}$ & $3(50)$ & $3(50)$ & $0(0)$ & $5(83.3)$ & $1(16.7)$ & $1(16.7)$ & $6(100)$ & $1(16.7)$ & $1(16.7)$ \\
\hline Citrobacter & $2(3.6)$ & $\mathrm{S}$ & $0(0)$ & $1(50)$ & $2(100)$ & $0(0)$ & $0(0)$ & $1(50)$ & $0(0)$ & $2(100)$ & $2(100)$ \\
\hline \multirow[t]{2}{*}{ spp } & & I & $0(0)$ & $0(0)$ & $0(0)$ & $0(0)$ & $2(100)$ & $1(50)$ & $0(0)$ & $0(0)$ & $0(0)$ \\
\hline & & $\mathrm{R}$ & $2(100)$ & $1(50)$ & $0(0)$ & $2(100)$ & $0(0)$ & $0(0)$ & $2(100)$ & $0(0)$ & $0(0)$ \\
\hline Proteus & $1(1.8)$ & $\mathrm{S}$ & $0(0)$ & $0(0)$ & $1(100)$ & $0(0)$ & $0(0)$ & $0(0)$ & $0(0)$ & $0(0)$ & $1(100)$ \\
\hline \multirow[t]{3}{*}{ spp. } & & I & $0(0)$ & $0(0)$ & $0(0)$ & $0(0)$ & $1(100)$ & $0(0)$ & $0(0)$ & $0(0)$ & $0(0)$ \\
\hline & & $\mathrm{R}$ & $1(100)$ & $1(100)$ & $0(0)$ & $1(100)$ & $0(0)$ & $1(100)$ & $1(100)$ & $1(100)$ & $0(0)$ \\
\hline & & $\mathrm{S}$ & $8(24.2)$ & $12(36.4)$ & $30(90.9)$ & $4(12.1)$ & $22(66.7)$ & 19(57.6) & $3(9.1)$ & $23(69.7)$ & $29(87.8)$ \\
\hline \multirow[t]{2}{*}{ Total } & & I & $5(15.2)$ & $9(27.3)$ & $3(9.1)$ & $2(6.1)$ & $6(18.2)$ & $5(15.1)$ & $8(24.2)$ & $7(21.2)$ & $2(6.1)$ \\
\hline & & $\mathrm{R}$ & $20(60.6)$ & $12(36.4)$ & $0(0)$ & $27(81.8)$ & $5(15.1)$ & $9(27.3)$ & $22(66.7)$ & $3(9.1)$ & $2(6.1)$ \\
\hline
\end{tabular}

$229 \mathrm{CIP}=$ ciprofloxacin, $\mathrm{NOR}=$ norfloxacin, $\mathrm{GEN}=$ gentamicin, $\mathrm{CRO}=$ ceftriaxone, $\mathrm{F}=$ Nitrofurantoin $230 \mathrm{AMP}=$ ampicillin $\mathrm{SXT}=$ trimethoprim/sulfamethoxazole. $\mathrm{NA}=$ Nalidixic acid, $\mathrm{MEM}=$ 231 meropenem, $\mathrm{R}=$ Resistant, $\mathrm{S}=$ Sensitive, $\mathrm{I}=$ Intermediate $\mathrm{ASP}=$ Antimicrobial susceptibility 232 pattern

233 Gram-Positive Bacteria

234 Gram-positive isolates were highly susceptible to GEN (95.7\%), F (82.6\%), clindamycin (69.6) 235 and K (72.7\%) while, resistant to SXT (95.7\%). CoNS which were the predominant isolates among 236 gram-positive were $100 \%$ resistance to SXT. Similarly, S. aureus also showed resistance to SXT 237 (85.7) and F (57.1) but was sensitive to GEN (100\%), F (71.4\%), and K (71.4\%). Enterococcus 238 species were $100 \%$ sensitive to NOR, CIP and F, but resistant to SXT (Table 3).

239 Table 3. Antimicrobial testing of Gram-positive bacteria isolated from urine culture of pregnant 240 women at Goba referral hospital, 2019

\begin{tabular}{|c|c|c|c|c|c|c|c|c|c|}
\hline \multirow{2}{*}{$\begin{array}{l}\text { Bacterial } \\
\text { isolate }\end{array}$} & \multirow{2}{*}{$\begin{array}{r}\text { Total } \\
\text { no(\%) }\end{array}$} & \multirow[b]{2}{*}{ ASP } & \multicolumn{7}{|c|}{ Antimicrobial agents/no of bacterial isolates (\%) } \\
\hline & & & GEN & SXT & NOR & CIP & $\mathbf{F}$ & CD & $\mathbf{K}$ \\
\hline S. aurues & $7(12.5)$ & $\mathrm{S}$ & $7(100)$ & $1(14.3)$ & $2(28.6)$ & $3(42.9)$ & $5(71.4)$ & $5(71.4)$ & $5(71.4)$ \\
\hline
\end{tabular}




\begin{tabular}{|c|c|c|c|c|c|c|c|c|c|}
\hline & & I & $0(0)$ & $0(0)$ & $1(14.3)$ & $2(28.6)$ & $0(0)$ & $1(16.7)$ & $0(0)$ \\
\hline & & $\mathrm{R}$ & $0(0)$ & $6(85.7)$ & $4(57.1)$ & $2(28.6)$ & $2(28.6)$ & $1(16.7)$ & $2(29.6)$ \\
\hline \multirow[t]{3}{*}{ CONS } & $15(26.8)$ & $\mathrm{S}$ & $14(93.3)$ & $0(0)$ & $8(53.3)$ & $6(40)$ & $13(66.7)$ & $11((73.3)$ & $11(73.3)$ \\
\hline & & I & $1(6.7)$ & $0(0)$ & $0(0)$ & $1(6.7)$ & $0(0)$ & $1(7.1)$ & $0(0)$ \\
\hline & & $\mathrm{R}$ & $0(0)$ & $15(100)$ & $7(46.7)$ & $8(53.3)$ & $2(13.3)$ & $3(21.4)$ & $4(26.7)$ \\
\hline \multirow{4}{*}{$\begin{array}{l}\text { Enterococcus } \\
\text { spp. }\end{array}$} & $1(1.8)$ & $\mathrm{S}$ & $0(0)$ & $0(0)$ & $1(100)$ & $1(100)$ & $1(100)$ & $0(0)$ & NA \\
\hline & & I & 1(100) & $0(0)$ & $0(0)$ & $0(0)$ & $0(0)$ & $1(100)$ & \\
\hline & & $\mathrm{R}$ & $0(0)$ & $1(100)$ & $0(0)$ & $0(0)$ & $0(0)$ & $0(0)$ & \\
\hline & & $\mathrm{S}$ & $53(95.7)$ & $1(4.3)$ & $11(47.8)$ & $10(43.5)$ & $19(82.6)$ & $16(69.6)$ & $16(72.7)$ \\
\hline \multirow[t]{2}{*}{ Total } & & I & $3(4.3)$ & $0(0)$ & $1(4.4)$ & $3(13)$ & $0(0)$ & $3(13)$ & $0(0)$ \\
\hline & & $\mathrm{R}$ & $0(0)$ & $22(95.7)$ & $11(47.8)$ & $10(43.5)$ & $4(17.4)$ & $4(17.4)$ & $4(27.3)$ \\
\hline
\end{tabular}

241

242

243

244

245

246

247

248

249

250

251

252

253

254

255

256

257

258

259

CONS- Coagulase-negative Staphylococcus, $\mathrm{CIP}=$ ciprofloxacin, $\mathrm{NOR}=$ norfloxacin, $\mathrm{GEN}=$ gentamicin, $\mathrm{F}=$ Nitrofurantoin $\mathrm{CD}=$ Clindamcyin $\mathrm{SXT}=$ trimethoprim/sulfamethoxazole. $\mathrm{K}=$ Kanamycin, $\mathrm{R}=$ Resistant, $\mathrm{S}=$ Sensitive, $\mathrm{I}=$ Intermediate ASP $=$ Antimicrobial susceptibility pattern

\section{Multiple drug resistance patterns of the isolates}

Multiple drug resistance (resistance to two or more antimicrobial drugs) was seen in all isolated pathogens $(100 \%)$. All isolates of bacteria were resistant to at least two antimicrobials. No isolates were susceptible to all drugs tested (Tables 2 and 3 ).

\section{Associated risk factors of UTIs}

The symptomatic and asymptomatic participants were almost equal in this study. Of the 234 women enrolled in study $54(23.1 \%)$ have had the previous history of UTI, $8(5.1 \%)$ history of a catheter, 15(6.4) history of catheterization and $136(58.1 \%)$ of the participants were used family planning previously (Table .2).

54 In bivariate logistic regression factors like the previous history of UTIs, symptoms of UTIs, history of a catheter, and history of gynecological surgery showed significant association $(\mathrm{p}<0.05)$. Multivariable logistic regression shown that the odds of acquiring UTIs in pregnant women that had the previous history of UTIs 4.42 times higher than those had no previous history(AOR=4.42; $95 \% \mathrm{CL}, 2.12-9.20, \mathrm{P}=0.00)$. Similarly, the risk of UTI infection was 5.75 times higher in those who have had the previous history of catheterization (Table .4). 
Table 4. Associated factors of UTIs among pregnant women attended MWU GRH ANC, 2019

\begin{tabular}{|c|c|c|c|c|c|}
\hline Characteristic & $\begin{array}{l}\text { Cultured } \\
\text { No. }(\%)\end{array}$ & $\begin{array}{l}\text { Significant } \\
\text { BacteriuriaNo.(\%) }\end{array}$ & $\operatorname{COR}(95 \%$ CL) & $\operatorname{AOR}(95 \% \mathrm{CL})$ & $\begin{array}{c}\text { P- } \\
\text { value }\end{array}$ \\
\hline \multicolumn{6}{|l|}{ History of UTI } \\
\hline Yes & $54(23.1)$ & $27(50)$ & $5.2(2.68-10.13) *$ & $4.42(2.12-9.20)^{*}$ & 0.00 \\
\hline No & $180(76.9)$ & $29(16.1)$ & 1 & 1 & \\
\hline \multicolumn{6}{|c|}{ Symptom of UTI } \\
\hline Yes & $115(49.1)$ & $37(32.2)$ & $2.49(1.33-4.68)^{*}$ & $0.49(0.24-1.01)$ & 0.64 \\
\hline No & $119(50.9)$ & $19(16)$ & 1 & 1 & \\
\hline \multicolumn{6}{|l|}{ Fever } \\
\hline Yes & $26(11.1)$ & $10(38.5)$ & $2.20(0.94-5.18)$ & $0.89(0.30-2.47)$ & 0.79 \\
\hline No & 208(88.9) & $46(22.1)$ & 1 & 1 & \\
\hline \multicolumn{6}{|c|}{ History of gynecological surgery } \\
\hline Yes & $12(5.1)$ & $8(66.7)$ & $7.25(2.09-25.1)^{*}$ & $0.49(0.10-2.29)$ & 0.37 \\
\hline No & $222(94.9)$ & $48(21.6)$ & 1 & 1 & \\
\hline \multicolumn{6}{|c|}{ History of kidney problem } \\
\hline Yes & $18(7.7)$ & $6(33.3)$ & $1.66(0.59-4.65)$ & $1.15(0.35-3.82)$ & 0.81 \\
\hline No & $216(92.3)$ & $50(23.1)$ & 1 & 1 & \\
\hline \multicolumn{6}{|c|}{ History of catheterization } \\
\hline Yes & $15(6.4)$ & $10(66.7)$ & $7.52(2.45-23.1)^{*}$ & $5.75(1.46-22.7)^{*}$ & 0.012 \\
\hline No & 219(93.6) & $46(21)$ & 1 & 1 & \\
\hline \multicolumn{6}{|c|}{ History of contraceptive } \\
\hline Yes & $136(58.1)$ & $35(25.7)$ & $1.27(0.68-2.36)$ & $0.99(0.49-2.01)$ & 0.99 \\
\hline No & $98(41.9)$ & $21(21.4)$ & 1 & 1 & \\
\hline \multicolumn{6}{|c|}{ History of diabetes Mellitus } \\
\hline Yes & $5(2.1)$ & $0(0.0)$ & & & \\
\hline No & 229(97.9) & $56(24.5)$ & 0 & 0 & \\
\hline
\end{tabular}

261 NB: COR; Crude Odd Ratio AOR; Adjusted Odd Ratio 
$*$ = statistically significant $(\mathrm{p}$-value $<0.05), \mathrm{COR}(95 \% \mathrm{CI})=$ crudes odds ratio at $95 \%$ confidence interval, $\mathrm{AOR}(95 \% \mathrm{CI})=$ adjusted odds ratio at $95 \%$ confidence interval

\section{DISCUSSION}

The current study has shown that $23.9 \%$ of pregnant women had UTIs in the course of their pregnancy. The overall prevalence of UTI in pregnant women in the current study is comparable to the prevalence of UTIs described in Buea health district, Cameroon $(23.5 \%),{ }^{9}$ Muhimbil National Hospital, Tanzania (21\%)[19], Nairobi, Kenya (26.7\%)[11], Hawassa, Southern Ethiopia (18.8\%)[20] and Ambo (18.7\%)[3] but relatively higher than the reports from Khartoum, Sudan (14\%)[17] Tikur Anbessa Specialized Hospital, Addis Ababa, Ethiopia (11.6\%)[21], University of Gondar Teaching Hospital, Northwest Ethiopia (10.4\%)[8] Jimma Specialized Hospital, Southwest Ethiopia (9.2\%)[22] and Dil Chora Referral Hospital, Dire Dawa, Eastern Ethiopia $(14 \%)[6]$. In contrast, this finding was lower than the study performed in Hodeida City, Yemen $(54.5 \%)[23]$. and Ghana (29.9\%)[24]. This difference may be enlightened by the changes in the environmental conditions, a method implemented $\&$ features of study populations such as societal and food habits and the standard of personal hygiene [25].

In this study, Gram-negative bacteria isolates were more predominant (58.9\%) than Gram-positive bacteria isolates (41.1\%). Similar results were reported in previous Ethiopian studies with (60\% vs. 40 \%) reported in Tikur Anbessa Specialized Hospital Addis Ababa [21] and (58.4\% vs. 41.6\%) in Gondar University Hospital [8] and elsewhere in the world [11,19]. The high percentage of isolation of Gram-negative uro-pathogens might be due to the existence of distinctive structure in Gram-negative bacteria which support for adhesion to the uro-epithelial cells and inhibit bacteria from urinary lavage, permitting for reproduction and tissue invasion[26]. E. coli was the most frequent etiological agent of UTI, which accounts for up to $42.9 \%$ of isolated bacteria. The current result is in agreement with the finding from Ethiopia [3,8,21]. It is also consistent with findings from Kenya and Cameroon [9,11]. E. coli was considered as the most dominant uro-pathogenic bacteria due to several virulence factors specific to colonization and invasion of the urinary epithelium [26]. The second common bacterial isolate was Coagulase-negative staphylococci (CoNS) and $S$. aureus, with an overall isolation rate of $26.8 \%$ and $12.5 \%$ respectively. A 
comparable result was reported in other studies conducted elsewhere[8,13,27]. Klebsiella species, Proteus species, Citrobacter species and Enterococcus species were also causative agents of UTIs. The prevalence of bacteriuria among symptomatic and asymptomatic pregnant women was $32.2 \%$ and $16 \%$ respectively. This result is higher than the studies conducted in Dil Chora, Ethiopia, and Sudan $[6,17]$. This is due to the study site is far from the center and the health care system is weak.

The prevalence of UTIs in pregnant women with a former history of UTIs was statistically significant $(p=0.00)$. This finding is comparable with earlier studies conducted in Ethiopia $[6,8]$ and elsewhere in Saudi Arabia [28]. This could be due to ineffective treatment or the occurrence of resistant strains from those who had a prior history of UTIs. The prevalence of UTIs in pregnant women with the previous history of catheterization was also significantly greater than those without a history of previous catheterization $(p=0.012)$. Similar findings were reported in Ethiopia $[8,27]$. But, other associated factors of bacteriuria in pregnancy like age, residence, marital status, occupation, level of education, socioeconomic status, gestational stage, history of gynecological surgery, kidney problem and gravidity were not showed a significant association. This is in agreement with numerous studies in Ethiopia[8,13,27] and Sudan [17].

This finding showed a higher percentage of resistance to regularly prescribed antimicrobial drugs. Most isolates of Gram-negative bacteria showed resistance to AMP, SXT and NA. However, Gram-negative isolates were showed high sensitivity to GEN and F. This is agreeing with the research conducted in Addis Ababa Ethiopia [21]. E. coli isolates were showed high resistance to AMP and SXT. The current result is marginally related to the finding from Dire Dawa [6] and Ambo [3]. A high level of resistance of Klebsiella species to AMP and NA were revealed in the study area. Citrobacter species and Proteus species were showed high resistance against AMP, SXT and NA.

Among Gram-positive bacteria tested, more than 70\% of the isolates were sensitive to GEN, F, CLD, and K. S. aureus showed resistance to SXT and NOR, while CoNS showed resistance to SXT. Enterococcus species were resistant to SXT but sensitive to NOR, CIP and F.

All bacteriological isolates of the present research exhibited resistance to at least two antimicrobials and no isolate was sensitive to all antibiotics tested. This correlates with the study 
324 done in Gondar university teaching hospital [8]. However, this result is higher than the report from

325 Tikur Anbesa specialized hospital [21]. A high prevalence of MDR reported in this study might

326 be due to the unhindered accessibility and high rate of use of non-prescribed drugs. It might also

327 be associated with the quick spread of resilient bacteria and a high frequency of mismanagement

328 of antimicrobials such as self-prescription, excessive use, failure to follow the standard treatment

329 guidelines and scarce or absence of antimicrobial drug resistance surveillance program [14,29].

\section{LIMITATIONS}

331 The limitation of this cross-sectional hospital-based study is that an equal number of study subjects from urban and rural parts were not included and hence this might limit interpretation of the finding to the general population of the area.

\section{CONCLUSION AND RECOMMENDATIONS}

335 This study showed an overall high prevalence of UTIs in pregnant women. E. coli were the most leading bacterial isolates followed by CoNS and $S$. aureus. An increasing percentage of resistance to the usually used antimicrobial agents has been observed for both Gram-negative and Grampositive isolates and multi-drug resistance has been shown in 100\% of bacterial isolates. GEN and F might be considered as alternative options in the management of UTIs. This study recommends that the early detection of the causative agents of UTIs and determining their antimicrobial sensitivity testing in pregnant women will help to confirm suitable management of UTI and to inhibit its additional problem in mother and fetus. Health education about the causes of UTI and

344 out, to isolate other causes of UTIs.

\section{Availability of data and materials}

346 There is no additional data; all data included in the manuscript.

\section{Competing Interest}

348 We verify that all the authors have agreed to share the outcome of this manuscript equally and are 349 no conflict of interest.

\section{$350 \quad$ Funding}

351 This study was funded by Madda Walabu University 
355 We thank Madda Walabu University for supporting this study. We would like to acknowledge all Goba Referral Hospital Laboratory staff for their cooperation during sample collection. Our deep gratitude also goes to all the study participants for their willingness to participate in this study.

\section{REFERENCES}

1. Rahimkhani M, Khavari-Daneshvar H, Sharifian R. Asymptomatic bacteriuria and pyuria in pregnancy. Acta Medica Iranica. 2008:409-12.

2. Okonko IO, Ijandipe LA, Ilusanya OA, Donbraye-Emmanuel OB, Ejembi J, Udeze AO, et al. Incidence of urinary tract infection (UTI) among pregnant women in Ibadan, SouthWestern Nigeria. Afr J Biotechnol. 2009;8(23).

3. Gessese YA, Damessa DL, Amare MM, Bahta YH, Shifera AD, Tasew FS, et al. Urinary pathogenic bacterial profile, antibiogram of isolates and associated risk factors among pregnant women in Ambo town, Central Ethiopia: a cross-sectional study. Antimicrob Resist Infect Cont. 2017;6(1):132.

4. Haider G, Zehra N, Munir AA, Haider A. Risk factors of urinary tract infection in pregnancy. JPMA. J Pakistan Med Assoc. 2010; 60(3):213.

5. Aseel MT, Al-Meer FM, Al-Kuwari MG, Ismail MF. Prevalence and predictors of asymptomatic bacteriuria among pregnant women attending primary health care in Qatar. WORLD FAMILY MEDICINE. 2009 1;7(4):10-3.

6. Derese B, Kedir H, Teklemariam Z, Weldegebreal F, Balakrishnan S. Bacterial profile of urinary tract infection and antimicrobial susceptibility pattern among pregnant women attending at Antenatal Clinic in Dil Chora Referral Hospital, Dire Dawa, Eastern Ethiopia. Therap clin risk manag. 2016; 12:251.

7. Mulu A, Moges F, Tessema B, Kassu A. Pattern and multiple drug resistance of bacterial pathogens isolated from wound infection at University of Gondar Teaching Hospital, Northwest Ethiopia. Ethiop med j. 2006; 44(2):125-31.

8. Alemu A, Moges F, Shiferaw Y, Tafess K, Kassu A, Anagaw B, et al. Bacterial profile and drug susceptibility pattern of urinary tract infection in pregnant women at University of Gondar Teaching Hospital, Northwest Ethiopia. BMC research notes. 2012 Dec 1;5(1):197. 
9. Mokube MN, Atashili J, Halle-Ekane GE, Ikomey GM, Ndumbe PM. Bacteriuria amongst pregnant women in the Buea Health District, Cameroon: Prevalence, predictors, antibiotic susceptibility patterns and diagnosis. PLoS One. 2013 Aug 16;8(8):e71086.

10. Ade-Ojo IP, Oluyege AO, Adegun PT, Akintayo AA, Aduloju OP, Olofinbiyi BA. Prevalence and antimicrobial susceptibility of asymptomatic significant bacteriuria among new antenatal enrollees in Southwest Nigeria. Intl Res J Microbiol. 2013 Sep;4(8):197203.

11. Nabbugodi WF, Gichuhi JW, Mugo NW. Prevalence of Urinary Tract Infection, Microbial Aetiology, and Antibiotic Sensitivity Pattern among Antenatal Women Presenting with Lower Abdominal Pains at Kenyatta National Hospital, Nairobi, Kenya. Open Access J SciTechnol. 2015; 3(3):1-6.

12. Matuszkiewicz-Rowińska J, Małyszko J, Wieliczko M. Urinary tract infections in pregnancy: old and new unresolved diagnostic and therapeutic problems. Archives med sci: AMS. 2015; 11(1):67.

13. Tazebew E, Beyene G, Tsegaye W, Melaku S. Associated risk factors of urinary tract infection among pregnant women at Felege Hiwot Referral Hospital, Bahir Dar, North West Ethiopia. BMC research notes, 2013; 6(1), p.292.

14. Cheesbrough M., 2006. Medical Laboratory Manual for Tropical Countries II. 255- 275.

15. Gebrekirstos NH, Workneh BD, Gebregiorgis YS, Misgina KH, Weldehaweria NB, Weldu MG, et al. Non-prescribed antimicrobial use and associated factors among customers in drug retail outlet in Central Zone of Tigray, northern Ethiopia: a cross-sectional study. Antimicrob Resist Infect Cont. 2017; 6(1):70.

16. Courvalin P, Trieu Cuot P. Minimizing potential resistance: the molecular view. Clin infect dis. 2001; 33(Supplement_3):S138-46.

17. Hamdan HZ, Ziad AH, Ali SK, Adam I. Epidemiology of urinary tract infections and antibiotics sensitivity among pregnant women at Khartoum North Hospital. Ann. clin microbiol antimicrob. 2011; 10(1):2.

18. Bauer AW. Antibiotic susceptibility testing by a standardized single disc method. Amer J clin pathol. 1966;45: 149-58. 
19. Moyo SJ, Aboud S, Kasubi M, Maselle SY. Bacterial isolates and drug susceptibility patterns of urinary tract infection among pregnant women at Muhimbili National Hospital in Tanzania. Tanzania J Health Res. 2010; 12(4):233-6.

20. Tadesse E, Teshome M, Merid Y, Kibret B, Shimelis T. Asymptomatic urinary tract infection among pregnant women attending the antenatal clinic of Hawassa Referral Hospital, Southern Ethiopia. BMC research notes. 2014 Dec 1;7(1):155.

21. Assefa A, Asrat D, Woldeamanuel Y, Abdella A, Melesse T. Bacterial profile and drug susceptibility pattern of urinary tract infection in pregnant women at Tikur Anbessa Specialized Hospital Addis Ababa, Ethiopia. Ethiop med j. 2008 Jul 1;46(3):227-35.

22. Beyene G, Tsegaye W. Bacterial uropathogens in urinary tract infection and antibiotic susceptibility pattern in Jimma University specialized hospital, southwest Ethiopia. Ethiop j health sci. 2011;21(2):141-6.

23. AL-Kadassy AM, Baraheem OH, Ogaili MA. The Prevalence of Urinary Tract Infection (UTI) Among Pregnant Women In Hodeidah City. IOSR J Dental Med Sci (IOSR-JDMS 2016;15(12), 105-109

24. Afriyie DK, Gyansa-Lutterodt M, Amponsah SK, Asare G, Wiredu V, Wormenor E, et al. Susceptibility pattern of uropathogens to ciprofloxacin at the Ghana police hospital. Pan Afri Med J 2015;22(1).

25. Shaifali I, Gupta U, Mahmood SE, Ahmed J. Antibiotic susceptibility patterns of urinary pathogens in female outpatients. North Amer J med sci. 2012 Apr;4(4):163.

26. Lavigne JP, Boutet-Dubois A, Laouini D, Combescure C, Bouziges N, Marès $P$, et al. Virulence potential of Escherichia coli strains causing asymptomatic bacteriuria during pregnancy. J clin microbiol. 2011; 49(11):3950-3.

27. Ferede G, Yismaw G, Wondimeneh Y, Sisay Z. The prevalence and antimicrobial susceptibility pattern of bacterial uropathogens isolated from pregnant women. Eur J Exp Biol. 2012;2(5):1497-502.

28. Al-Sibai MH, Saha A. and Rasheed P. Socio-biological correlate of bacteruria in Saudi pregnant women. Public health, 1989; 103(2), pp.113-121.

29. DACA. Antimicrobials use, resistance and containment baseline survey syntheses of findings, august 2009, Addis Ababa, Ethiopia. 
Figures

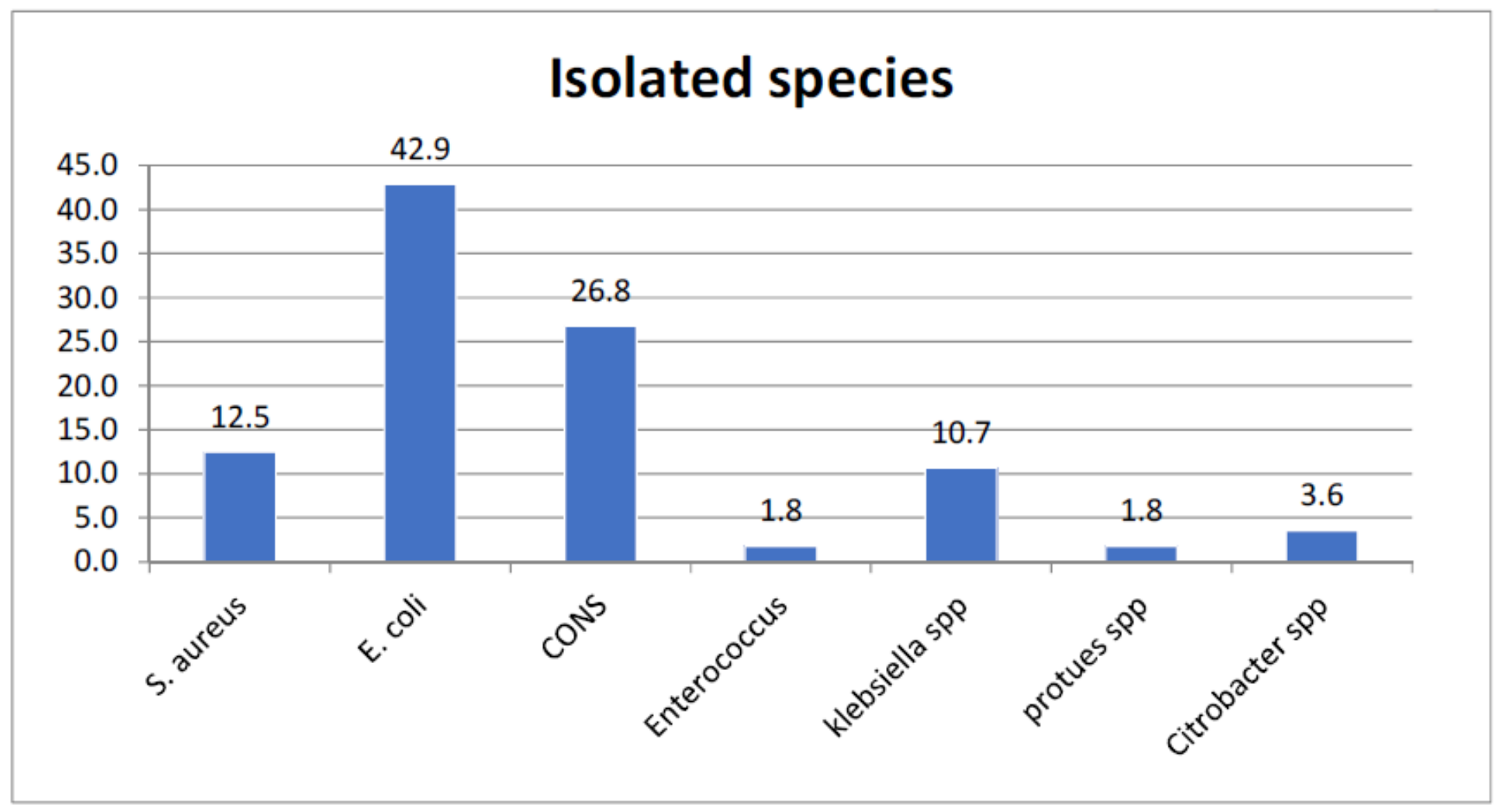

CONS - Coagulase-negative Staphylococcus

Figure 1

Bacterial isolates among pregnant women in MWU GRH, Southeast Ethiopia. 